\title{
A Study of Spinal Anaesthesia in Paediatric patients of aged 2-8 years
}

\author{
Authors \\ Sanjay S Bule ${ }^{1}$, Ramesh N Sungandh ${ }^{2}$, Kavita G Irkhede ${ }^{3}$, Savita R Sugandh ${ }^{4}$ \\ Corresponding Author \\ Dr Sanjay S Bule
}

Department of Anaesthesia, Government Medical College \& Hospital, Nagpur-3 Maharashtra India Email: sanjay.bule@ rediffmail.com,Phone no:- +919657250781

\begin{abstract}
Background: In Paediatric Patients Spinal Anaesthesia is used for subumbilical surgeries but still there is a concern about its safety \& feasibility. In our prospective study the main objective was to reevaluate the hemodynamic stability \& any complications occurred in paediatric spinal anaesthesia.

Material and Methods: In this prospective study, 40 paediatric patients of aged 2-8 years were included undergoing subumbilical surgery. Under all aseptic precautions and sedation, SubArachnoid block was given with $26 \mathrm{~g}$ hypodermic needle through L3-LA or LA-L5 interspinalspace \& hyperbaric 0.5\%Bupivacaine was administered according to the weight of children. .The dose of Bupivacaine used was $0.1 \mathrm{ml} \mathrm{kg}$ for child $(<5 \mathrm{~kg}), 0.08 \mathrm{mN} \mathrm{kg}(5-15 \mathrm{~kg}), 0.06 \mathrm{mN} \mathrm{kg}(>15 \mathrm{~kg})$. Demographic data, vital parameters, sensory -motor block characteristics \& complications were noted.

Results: There was no significant change in vital parameters. Mean peak sensory level was T $6.20 \pm 1.20$ (T4T8).Mean sensory level at the end of surgery was T8.11 $\pm 1.42(T 6-T 12)$ Modified Bromage score was 3 in all patients. Sensory and Motor block recovery was complete in all patients. Mean time to two segment regression was 42.91 $\pm 10.72(30-70)$ min .Incidence of complications was minimal with shivering in 2 patients $(5 \%)$ difficulty in breathing in 1 patient $(2.5 \%)$ \& also in 1 patient $(2.5 \%)$ nausea \& vomiting.

Conclusion: Paediatric spinal anaesthesia is safe feasible \& effective anaesthetic technique for subumbilical surgeries of limited duration (70-80) minutes with negligible side effects.
\end{abstract}

Keywords- Paediatric; spinal anaesthesia; infraumbilical; complications; hemodyamics.

\section{Introduction}

Regional anaesthesia in children was first studied by August Bier in 1899. In 1900, Bainbridge reported a case of strangulated hernia repair under spinal anaesthesia in an infant of three months. Thereafter, in 1909-1910 Tyrell Gray, a British surgeon published a series of 200 cases of lower abdominal surgeries in infants and children under spinal anaesthesia $^{1,2,3,4}$. After some years it fell into disuse because of the introduction of various muscle relaxants and inhalational agents and was almost unused after World War II. In the last decade, it started being advocated again by many centers due to increasing knowledge on pharmacology, safety information and availability of specialized equipment for regional anaesthetic techniques and monitoring in children. In the coming times, paediatric spinal anaesthesia will not only be used in cases where general anaesthesia is risky or contraindicated but also be the preferred choice in most lower abdominal and lower extremity surgeries in children. Spinal anaesthesia is gaining 
popularity in infants \& children but its safety, feasibility \& reliability can be established with greater use \& research. only. Hence we design this prospective study to analyzes the hemodynamic stability \& to observe any complications related to spinal anaesthesia in paediatric patients aged 2-8 years of age.

Aims and Objectives: To study the effect of spinal anesthesia in paediatric patients in terms of

1) Study the perioperative haemodynamic changes.

2) Study the occurrence of any adverse events.

\section{Materials \& Methods}

After approval of Institutional Ethical Committee this study was conducted in 40 patients .Informed consent was obtained from parents of each child included in this study. All paediatric patients from 2 to 8years of age group, American society of anesthesioly grade I-II, without any cardiorespiratory abnormility scheduled for elective infraumbilical surgeries like congenital inuinal hernia, congenital hydrocele, undescended testis, hypospadiasis, fracture shaft femur, were selected. Total 40 cases were done. The preanaesthetic check up was done one day prior of scheduled day surgery. Patients with known contraindictation to spinal anaesthesia were excluded.

All patients were kept nil by mouth for 6hrs (solid) and 3 hours (clear fluid) before anaesthesia. Relevant investigation were done e.g. haemoglobin, complete blood count, kidney function test etc. Special investigation like chest xray, coagulation profile only if needed. On the day of surgery in preoperative room vital parameters (Heart Rate, Respiration, Blood Pressure, Spo2) were noted \& iv line was established.All patients were premedicated with iv midazolam $0.03 \mathrm{mglkg}$ body weight, iv glycopyrolate 4 microgm $\mathrm{kg}$ body weight. After that when child became calm, was taken inside OT keeping all emergeny drugs, endotracheal tubes of appropriate sizes, Laryngoscopes,\& JRM Circuit ready. Multipara monitor for Heart rate, noninvasive Blood pressure, spo 2 , respiratory rate $\&$ temperature monitering attached. All above baseline vital parameters were noted \& Iv fluid ringer lactate $5 \mathrm{ml} \mid \mathrm{kg}$ was given over 15 minutes. To keep the child immobile and cooperative iv ketamine was given in $1 \mathrm{mg} \mathrm{kg}$ body weight \& o2 with mask was given at 3-4 litlmin given. Then under all aseptic precautions Subarachnoid block was given via midline approach with $26 \mathrm{~g}$ hypodermic needle through L3-L4 or L4-L5 interspinal space in left lateral position. After getting free flow of CSF, $0.5 \%$ hyperbaric Bupivaccaine was given intrathecally according to the weight of child. The end of spinal drug injection was taken as zero hour for further data recording. After injecting the drug, child was kept supine for 10 minutes. vitals Heart Rate, systoli-distolic blood pressure, Respiratory Rate, SPO2, Temperature were recorded every 1 minutes for first 10 minutes $\&$ then every 10 minutes till the completion of surgery. In paediatric patient it was very difficult to assess the onset \& level of sensory $\&$ motor block as child was sedated \& difficulty in understanding our commands. Arbitrarily, we checked the response of child by pin prick with plastic tip of iv set and to firm skin pinch and assessed the response of child to that dermatomal level5. The desired peak sensory level was aimed to be at T10 level for defining the successful Spinal Anaesthesia Similarly modified Bromage scale was assessed by pin prick given on thigh \& observed the response of lower limbs \& modified Bromage scale was noted. After 10 minutes of spinal Anaesthesia if peak sensory level was T10 and or Bromage scale was 3 surgery was allowed to start .If there was no response to surgical stimulus it was considered as successful spinal Anaesthesia block (Grade A.)If the peak sensory level was below T10 and or Bromage scale was $<3$ then it was defined as failed spinal anaesthesia block. (Grade C)And these cases were done under General Anaesthesia and it was excluded from study. All successful spinal block patients were kept sedated intermittently with o2 \& sevoflurane on spontaneous respiration with JRM Circuit when child was crying without pain but due to new surrounding environment inside OT. If intraoper-atively pain, or 


\section{JMSCR Vol||05||Issue||03||Page 19254-19259||March}

lack of relaxation was observed supplemental anaesthesia was given in the form of intravenous (iv) ketamine $1 \mathrm{mg} \backslash \mathrm{kg}$ along with iv propofol $1 \mathrm{mg} / \mathrm{kg}$ and $\mathrm{O} 2$ and sevoflurane was given with JRM Circuit on spontaneous respiration and the case was considered as partial spinal block. (Grade B)At the end of surgery all patients received Paracetomol suppository $(20 \mathrm{mg} \backslash \mathrm{kg}$ ) was given. After surgery all patients were transferred to post Anaesthesia care unit for monitoring of vital signs \& regression of block till the complete reco-very of spinal anaesthesia \& that time was noted .

Demographic data, Type \& duration of surgery, Vital parameters were noted. Requirement of supplemental sedation, local anaesthetic dose used, $\&$ number of attempts for lumber puncture were noted. Quality of Sensory block, motor block,\& complications related to spinal anaesthesia, such as total spinal, high spinal, vomiting, shivering, urinary retention, post dural puncture headache, neurological deficit were recorded. The patients were monitored until full recovery. The data analyzed using MS Excel and IBM SPSS 16.0 (Statistical Package for the social Sciences)

Table 1 Showing Demographic characteristics

\begin{tabular}{|l|c|}
\hline Variables & Findings \\
\hline Mean Age (years) & $5.17+2.83(2-8)$ \\
\hline 'Mean Weight $(\mathrm{Kg})$ & $15.23+7.43(7.8-23)$ \\
\hline Sex(malelfemale) $\{\%\}$ & $32(80 \%) \backslash 8(20 \%)$ \\
\hline
\end{tabular}

Table 2 Type of Surgery \& its individual number

\begin{tabular}{|l|c|}
\hline Type of Surgery & Number(n=40) \\
\hline Congenital Hernia & 18 \\
\hline Congenital Hydrocele & 8 \\
\hline Undescended Testis & 6 \\
\hline Hypospadiasis & 4 \\
\hline Nailing for fracture shaft Femur & 3 \\
\hline Debridement of Wound in lower limb & 1 \\
\hline
\end{tabular}

Table 3: Showing Characteristics of Subarachnoid Block

\begin{tabular}{|l|l|}
\hline $\begin{array}{l}\text { sensory \& Motor Block } \\
\text { Charactertics }\end{array}$ & Observations \\
\hline Mean Peak Sensory Level & T 6.20+1.20 (T4-T8) \\
\hline $\begin{array}{l}\text { Mean Sensory level at the end } \\
\text { of surgery }\end{array}$ & T 8.11+1.3 (T6-T12) \\
\hline $\begin{array}{l}\text { Time to two segment } \\
\text { Regression (min) }\end{array}$ & $42.91+10.72(30-70)$ \\
\hline Modified Bromage Score 3 & $90 \%$ \\
\hline
\end{tabular}

In successful spinal cases, mean peak sensory level after 10 minute of SAB was T6.20+1.20(T4-T8) and the median was T6. Mean sensory level at the end of surgery was T8.11+1.42 (T6-T12) and the median was $\mathrm{T} 8$.In all successful spinal block the modified bromage scale was 3 which was seen in $90 \%$ of patients. Mean time to two segment regression was $42.91+10.72(30-70)$ min .Sensory and motor block recovery was complete in all patients.

Table 4 : vital Parameters

\begin{tabular}{|c|c|c|c|c|c|}
\hline $\begin{array}{l}\text { Timing of } \\
\text { Observation }\end{array}$ & $\begin{array}{c}\mathrm{SBP}(\mathrm{mmh} \\
\mathrm{g})\end{array}$ & $\begin{array}{c}\mathrm{DBP}(\mathrm{mmh} \\
\mathrm{g})\end{array}$ & $\begin{array}{c}\mathrm{HR} \backslash \mathrm{mi} \\
\mathrm{n}\end{array}$ & $\begin{array}{c}\mathrm{RR} \backslash \mathrm{mi} \\
\mathrm{n}\end{array}$ & $\begin{array}{c}\text { SPO2 } \\
\%\end{array}$ \\
\hline Before SAB & $85(78-96)$ & $64(66-70)$ & $\begin{array}{c}98(100 \\
-120)\end{array}$ & $\begin{array}{c}14(13- \\
15)\end{array}$ & 100 \\
\hline $\begin{array}{l}\text { After } \\
\text { Premedicati } \\
\text { on }\end{array}$ & $92(80-97)$ & $62(63-72)$ & $\begin{array}{c}110(98 \\
-135)\end{array}$ & $\begin{array}{c}13(11- \\
14)\end{array}$ & 99 \\
\hline $\begin{array}{l}\text { 5minutes } \\
\text { after SAB }\end{array}$ & $90(80-95)$ & $67(60-70)$ & $\begin{array}{l}105(11 \\
6-128)\end{array}$ & $\begin{array}{c}12(10- \\
13)\end{array}$ & 100 \\
\hline $\begin{array}{l}10 \text { minutes } \\
\text { after } \mathrm{SAB}\end{array}$ & $86(78-93)$ & $64(62-72)$ & $\begin{array}{c}100(97 \\
-120) \\
\end{array}$ & $\begin{array}{c}10(9- \\
11)\end{array}$ & 100 \\
\hline $\begin{array}{l}20 \text { minutes } \\
\text { after } \mathrm{SAB}\end{array}$ & $84(76-94)$ & $59(60-66)$ & $\begin{array}{c}94(92- \\
1190 \\
\end{array}$ & $\begin{array}{c}14(12- \\
16)\end{array}$ & 100 \\
\hline $\begin{array}{l}60 \text { minutes } \\
\text { after } \mathrm{SAB}\end{array}$ & $87(80-94)$ & $62(63-72)$ & $\begin{array}{c}89(90- \\
103) \\
\end{array}$ & $\begin{array}{c}14(12- \\
16)\end{array}$ & 100 \\
\hline $\begin{array}{l}\text { PACU } \\
\text { ROOM }\end{array}$ & $88(77-96)$ & $66(62-72)$ & $\begin{array}{c}95(99- \\
108)\end{array}$ & $\begin{array}{c}13(12- \\
14)\end{array}$ & 100 \\
\hline
\end{tabular}

There was no significant changes in the mean value of systolic blood pressure, diastolic blood pressure, respiratory rate, and oxygen saturation after subarachnoid block at all time period. Heart rate showed increases to $110(11.2 \%)$ after $5 \mathrm{~min}$ of subarachnoid block as compared to baseline..This can be due to glycopyrolate \& ketamine which were used for premedication \& before giving SAB. However afterwards mean heart rate showed no significant change from baseline. Only one patient developed difficulty in breathing immediately after SAB but there was no fall in oxygen saturation \& managed with oxygen on mask with JRM circuit on spontaneous respiration

Table 5 Number of patients Showing Intraoperative complications

\begin{tabular}{|l|c|}
\hline Complications Noted & Number of Patients \\
\hline Difficulty in Breathing & 1 \\
\hline Shivering & 2 \\
\hline Nausea \& Vomiting & 1 \\
\hline
\end{tabular}


Difficulty in Breathing was noted in one patient $(2.5 \%)$ which was managed with oxygen on mask and patient get stable in 10 minutes. Shivering was noted in two patients (5\%) and treated with iv pentazocine $0.2 \mathrm{mg} \mid \mathrm{kg}$. Nausea \& vomiting observed in one patient $(2.5 \%)$ and treated with iv ondansterone $0.1 \mathrm{mg} \mathrm{kg}$. No other complications was noted such as bradycardia, hypotension, urinary retention, total spinal, \& neurological deficit .

Table: 5 Number of patients operated in different grades of Spinal Anaesthesia

\begin{tabular}{|l|c|}
\hline Grades of Spinal Anaesthesia & $\begin{array}{c}\text { Number of patients } \\
\text { operated }(\mathrm{n}=40)\end{array}$ \\
\hline $\begin{array}{l}\text { Grade A( withouy any iv } \\
\text { supplementation) }\end{array}$ & $36(90 \%)$ \\
\hline $\begin{array}{l}\text { Grade B ( With once intraoperative iv } \\
\text { supplementation) }\end{array}$ & $2(5 \%)$ \\
\hline $\begin{array}{l}\text { Grade C ( conversion to GENERAL } \\
\text { ANAESTHESIA) }\end{array}$ & $2(5 \%)$ \\
\hline
\end{tabular}

Total thirty six patients (90\%) were operated under spinal anaesthesia without any intravenous supplementation.

Two patients $(5 \%)$ were operated along with once intravenous supplementation.

Two patients (5\%) were operated after conversions into general anaesthesia in view of inadequate spinal effect.

\section{Discussion}

This prospective study was done to evaluate the perioperative haemodynamic changes, feasibility\& safety of spinal anaesthesia in paediatric patients of 2- 8 years of age. In many studies it was shown that spinal anaesthesia in children is safe, cost effective $\&$ ideal for day case subumbilical surgeries $\&$ also very useful in limited resources. As compared to general anaesthesia decreased stress response \& recovery is very fast following spinal anaesthesia ${ }^{6}$. Since the childrens are uncooperative, crying during any invasive procedure adequate premedicaton in the form of analgesia \& sedation is very important for smooth regional procedures. Thus to make the child sedated, calm and thus cooperative during lumber puncture It may be supplimented by iv ketemine, and iv midazolam, or iv propofol, or inhalations anaesthetics Sevoflurane during the procedure.

In our study premedication was done with iv midazolam $0.03 \mathrm{mglkg}+$ iv glycopyrolate 4 microgmlkg in preoperative room. Inside the operation theatre, iv Ketamine $1 \mathrm{mg} \backslash \mathrm{kg}$ was given before lumber puncture \& o2 with mask was given. In left lateral position after cleaning \& draping of lumber area, with $26 \mathrm{~g}$ hypodermic needle lumber puncture was done at L3-L4 or L4-L5 space \& with clear free flow of CSF $0.5 \%$ heavy Bupivaccaine was injected according to the weight of children. During lateral position the neck was in extension as cervical flexion may obstruct the airway during the procedure. After that child was kept supine \& intraoperatively children was kept sedated with $\mathrm{O} 2$ and sevoflurane on mask with JRM circuit on spontaneous respiration intermittently when they were moving the upper part of body.

Sedative effects of SAB itself have also been documented in the literature. Hermanns et al(2006) 7.conducted the study to evaluate the sedation during spinal anaesthesia in infants. The presumaed mechanism for sedation after $\mathrm{SAB}$ is decreased afferent conduction to reticulo-thalamo-cortical projection pathways which reduces the excitability $\&$ arousal level of brain.In our study lumber puncture was successful in first attempt in 24 childrens $(60 \%) \&$ second attempt in 16 childrens (40\%). Not more then two attempts are required for lumber puncture which proved the ease $\&$ feasibility of procedure in well sedated childrens. The volume of CSF is more in spinal space \& these affects the pharmacokinetics of intrathecal drugs Among the various drugs approved by FDA for paediatric intrathecal use $0.5 \%$ bupivacaine both hyperbaric \& isobaric are commonly used. Baricity is one of the most significant factor to affect the distribution of local anaesthetic agent and hence success \& spread of the level of spinal blockade.

Cardiovascular changes related to spinal anaesthesia are less common in children then in adults. Children younger than 5-8 years of age have immature sympathetic nervous system and relatively small intravascular volume in the lower extremities \& 
splanchic system which limits the venous pooling in this group.

In our study the desired sensory level of T10 was achieved in $90 \%$ of patients after 10 minute of SAB $\&$ they were considered as successful spinal blockade (GradeA). In 5\% of patients intraoperative iv ketamine $1 \mathrm{mg} \backslash \mathrm{kg}+$ iv propofol $1 \mathrm{mg} \backslash \mathrm{kg}$ was given along with $\mathrm{O} 2$ \& Halothane with JRM circuit on spontaneous respiration and surgery was completed. In $5 \%$ of patients T10 level was not achieved after 10 minutes of SAB \& hence general anaesthesia was given for surgery \& considered as failed spinal block (Grade C)

The mean peak sensory level was T6.20 + 1.20 and the mediam was T5. Meantime two segment regression was $42.91+10.72(30-70) \mathrm{min}$. Since the level of surgery was below T10in all the patients adequate dermatome level was present until the end of surgery. Ahmed et al (2010)8 conducted the study on 78 children aged between 2-6 years of age undergoing different types of surgeries in the lower part of body \& observed that sensory block showed wide variation of level of spinal block from T1-T7 and median was T4 It is speculated that the drug uptake is faster in the SAB space in children owing to proportionally greater blood flow to the spinal cord as compared to adults. With faster drug distribution \& elimination childrens spinal block regression is 5 times faster than in adults. This restricts the use of $\mathrm{SAB}$ in surgeries of duration 60-70 minutes .

The most common complications in our study observed was Shivering. It was noted in 2 patients $(5 \%)$ and was treated with iv pentazocine $0.3 \mathrm{mg} \mathrm{kg}$. One patient developed difficulty in breathing immediately after SAB \& was managed with $\mathrm{O} 2$ on mask with JRM circuit on spontaneous respiration gets cured within 10 minutes. One patient developd nausea \& vomiting \& was managed with iv ondensterone $(0.8 \mathrm{mg} \mathrm{kg})$. No other complications noted such as total spinal, hypotension, bradycardia, urinary retention \& any neurological deficit.

Ahmed et al (2010)8 conduc ted the study to evaluate the characteristics of spinal blockade on 78 children aged between 2-6 years \& reported that shivering occurred in 5 patients \& vomiting noted in 1 patient, 2 patients suffered from hypotension which was treated with iv ephedrine $\&$ bradycardia was noted in 1 patient which was treated with iv atropine

Devendra verma et al (2014)9 studied spinal anaesthesia in infants \& children and noted shivering in $2.9 \%$ \& hypotension in $2 \%$ of patients.

\section{Conclusion}

In our experience no gross intraoperative hemodynamic changes observed \& also no permanent adverse complications occurred. The technique of spinal anaesthesia provides a good alternative to general anaesthesia in paediatric patients with increased general anaesthesia related risks (Malignant Hyperthermia, Difficult airway, Laryngospasm, delayed recovery etc), \& for patients undergoing lower abdominal or lower extremity surgery, lasting less than 60-70 minutes of duration. Economically also spinal anaesthesia is very cheap compared to general anaesthesia .Since our number of study patients were very less this topic requires large number of studies of paediatric patients for further confirming our observations .

\section{Source of support: Nil \\ Conflict of Interest: Nil}

\section{References}

1. Gray HT. A study of spinal anaesthesia in children and infants from a series of 200 cases. I Lancet. 1909;2:913-6.

2. Gray HT. A study of spinal anaesthesia in children and infants from a series of 200 cases. II Lancet. 1909;2:991-4.

3. Gray HT. A study of spinal anaesthesia in children and infants from a series of 200 cases. III Lancet. 1910;1:1611-5.

4. Somri M, Gaitini LA, Vaida SJ, Malatzkey S, Sabo E, Yudashkin M, et al. The effectiveness and safety of spinal anaesthesia in the pyloromyotomy procedure. Paediatr Anaesth. 2003;13:32-7. [Pub Med] 
5. Williams RK, Adams DC, Aladjem EV, Kreutz JM, Sartorelli KH, Vane DW, et al. The safety and efficacy of spinal anesthesia for surgery in infants: The Vermont Infant Spinal Registry. Anesth Analg. 2006; 102:67-71.

6. Goyal R, Jindal K, Baj B, Singh S, Kumar S. Pediatric spinal anesthesia. Indian J Anaesth. 2008;52:264-70.

7. Hermanns H, Stevens MF, Werdehausen R, Braun S, Lipfert P, Jetzek-Zader M. Sedation during spinal anaesthesia in infants. Br J Anaesth. 2006;97:380-4

8. Ahmed M, Ali NP, Kabir SM, Nessa M. Spinal anaesthesia: Is it safe in children. JAFMC Bangladesh. 2010;6:25-8.

9. Devendra Verma,Udita Naithani.et al Spinal Anaesthesia in infants and Children : A one year prospective audit.Anaesthesia Essays and Researchers ,2014 Sep-Dec 8(3),324329.

10. Bannister J ,McClure JH, Wildsmith JA.Effect of glucose concentration on the intrathecal spread of $0.5 \%$ Bupivacaine . BrJ Anaesth 1990;64:232-4 